\title{
CLASSIFICATION AND ASSESSMENT OF THE LAND USE - LAND COVER CHANGES IN JODHPUR CITY USING REMOTE SENSING TECHNOLOGIES
}

\author{
Madhur Aditya Saharan ${ }^{1}$, Nikhil Vyas ${ }^{2}$, S.L. Borana ${ }^{3, *}$, S.K. Yadav ${ }^{3}$ \\ ${ }^{1}$ Mahindra École Centrale College of Engineering, Hyderabad, India - aditya160126@ mechyd.ac.in \\ ${ }^{2}$ Indian Institute of Information Technology, Surat, India - nikhilvyas1998@ gmail.com \\ ${ }^{3}$ DL, Jodhpur, India - sohanlb@gmail.com, skyadavgeo@gmail.com
}

Commission V, SS: Infrastructure and Development Planning

KEY WORDS: Remote Sensing, LULC Classification, Landsat, Assessment, Change Detection.

\begin{abstract}
:
Land Use - Land Cover (LULC) classification mapping is an important tool for management of natural resources of an area. The remote sensing technology in recent times has been used in monitoring the changing patterns of land use-land cover. The aim of the study is to monitor the LULC changes in Jodhpur city over the period 1990 - 2018. Satellite imagery of Landsat 8 OLI (June, 2018) \& Landsat TM (Oct, 1990) were used for classification analysis. Supervised classification-maximum likelihood algorithm is used in ENVI software to detect land use land cover changes. Five LULC categories were used, namely- urban area, mining area, vegetation, water bodies and other area (Rock outcrops and barren land). The LULC classified maps of two different periods i.e. 2018 and 1990 were generated on 1:50,000 scale. The accuracy assessment method was used to measure the accuracy of classified maps. This study shall be of good assistance to the town planners of Jodhpur city for the purpose of the sustainable development as per the master plan 2031.
\end{abstract}

\section{INTRODUCTION}

Remote sensing (RS) is in general defined as the process of acquiring information about an object, area or phenomenon without being in physical contact with it (Lillesand et al., 2004; Campbell, 2002). Currently the term is used for satellites and even aircrafts carrying sensors in acquiring information regarding land surface, oceans, glaciers, air currents, etc.

Land use refers to the human induced changes for agricultural, industrial, residential or recreational purposes and Land cover features that are present on the earth's surface (Ramachandra and Bharath, 2012). Jodhpur is the second largest city of Rajasthan with population of 1.05 million. Over the years the city landscape saw significant changes due to growth of core and ancillary industries in north and south west part. The urbanization and availability of higher education opportunities facilitate immigration of labors and qualified professionals. These immigration population creates challenges to the local city planners for creating new public amenities with all urban facilities based on 2031 master plan. Geographical techniques are proven tools for mapping and monitoring land use for proper classification and assessment. In recent years, most urban land-use land cover studies have employed data from Landsat satellite (Herold et al., 2002). Classification of Landsat images of Jodhpur, India of two different years 1990 and 2018 have been incorporated in this study of LULC. Landsat series satellites were first launched in 1972 with Landsat 1 which was de-orbited in 1978. Eight Landsat satellites have been used for GIS studies and currently 3 satellites, such as Landsat 5, 7 and 8 , are in orbits. Description of spectral bands and ground resolution of Landsat OLI is shown in Table-1. The images formed by satellites have various bands and ENVI software allows in forming various band combinations. Every band has provided with different colours, wavelength and resolution assigned for this LULC study (Table-2).
For this study, ENVI (Environment for Visualizing Images) Software is used to classify different land cover features. ENVI is used for visualizing, analysing, and presenting different type of digital satellite images. Image-processing application is helpful in advanced, spectral tools, geometric correction, terrain analysis, radar analysis, raster and vector GIS capabilities.

\section{STUDY AREA}

The city of Jodhpur was considered for this research. Jodhpur city is located in North West region of India in state of Rajasthan. The spatial location of city is $26^{\circ} 18^{\prime} \mathrm{N}$ latitude and $73^{\circ} 04^{\prime} \mathrm{E}$ longitude and an average altitude of $224 \mathrm{~m}$ above mean sea level. The Study Area comprises of approx. $600 \mathrm{sq} \mathrm{km}$ (Fig.1).

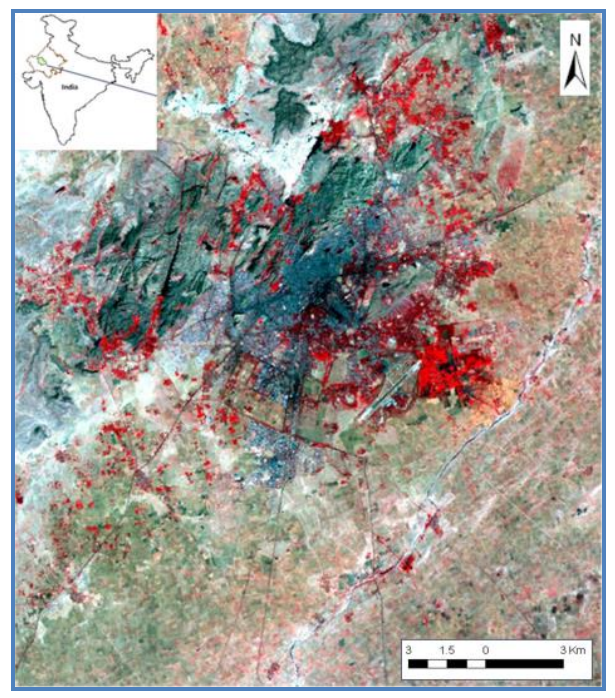

Figure 1. Satellite Image of Study Area.

\footnotetext{
* Corresponding author
} 


\begin{tabular}{|l|l|l|l|}
\hline Band Number & Wavelength $(\boldsymbol{\mu m})$ & Resolution & Colour \\
\hline 1 & $0.433-0.453$ & 30 & Coastal \\
\hline 2 & $0.45-0.515$ & 30 & Blue \\
\hline 3 & $0.525-0.6$ & 30 & Green \\
\hline 4 & $0.63-0.68$ & 30 & Red \\
\hline 5 & $0.845-0.885$ & 30 & NIR \\
\hline 6 & $1.56-1.66$ & 60 & SWIR \\
\hline 7 & $2.1-2.3$ & 30 & SWIR \\
\hline 8 & $0.5-0.68$ & 15 & PAN \\
\hline 9 & $1.36-1.39$ & 30 & Cirrus \\
\hline 10 & $10.6-11.2$ & 100 & Thermal \\
\hline 11 & $11.5-12.5$ & 100 & Thermal \\
\hline
\end{tabular}

Table 1. Spectral bands and resolution of Landsat OLI.

\begin{tabular}{|l|c|c|c|}
\hline Band Combinations & R & G & B \\
\hline Natural Colour & 4 & 3 & 2 \\
\hline False Colour (Urban) & 7 & 6 & 4 \\
\hline Colour Infrared (Vegetation) & 5 & 4 & 3 \\
\hline Agriculture & 6 & 5 & 2 \\
\hline Atmospheric penetration & 7 & 6 & 5 \\
\hline Healthy Vegetation & 5 & 6 & 2 \\
\hline Land/Water & 5 & 6 & 4 \\
\hline Vegetation Analysis & 6 & 5 & 4 \\
\hline
\end{tabular}

Table 2. Available bands combinations for various applications.

\section{MATERIALS AND METHODOLOGY}

\subsection{Materials}

Two Data sets were used in this research. Satellite data that comprised of two years multi - temporal satellite imageries Landsat TM imageries of 1990 and Landsat OLI 8 of 2018 (Table-3, Figure-2 and 3) acquired from the USGS GLOVIS website. Secondary data incorporated are the ground truth (GT) data for the LULC feature classes (Table-4). The GT data were in the form of location points collected using GPS for the image analysis and used for classification analysis and assessment of classification accuracy (Jensen et al. 2005).

\begin{tabular}{|l|l|l|l|}
\hline $\begin{array}{l}\text { Satellites/ } \\
\text { Sensors }\end{array}$ & Resolution & Path/Row & Acquisition Date \\
\hline Landsat TM & $30 \mathrm{~m}$ & $149 / 42$ & $29-10-1990$ \\
\hline Landsat TM & $30 \mathrm{~m}$ & $149 / 42$ & $01-06-2018$ \\
\hline
\end{tabular}

Table 3: Characteristics of Satellite Data Used.

\begin{tabular}{|c|c|l|}
\hline \multicolumn{2}{|c|}{ LULC Classes } & \multicolumn{1}{|c|}{ Description } \\
\hline 1 & Urban area & $\begin{array}{l}\text { Commercial, residential, industrial and } \\
\text { transportation infrastructures. }\end{array}$ \\
\hline 2 & Vegetation & $\begin{array}{l}\text { Describes areas with Forest, grass, trees } \\
\text { and shrubs trees }\end{array}$ \\
\hline 3 & $\begin{array}{c}\text { Mining } \\
\text { Area }\end{array}$ & Sandstone Mining quarry of clusters. \\
\hline 4 & $\begin{array}{c}\text { Water } \\
\text { bodies }\end{array}$ & $\begin{array}{l}\text { Areas covered with River, open water, } \\
\text { lakes, ponds and reservoirs. }\end{array}$ \\
\hline 5 & $\begin{array}{c}\text { Rock } \\
\text { outcrops }\end{array}$ & features such as rocks hillocks. \\
\hline 6 & Other Area & $\begin{array}{l}\text { This class defines Crop fields, fallow lands, } \\
\text { barren area. }\end{array}$ \\
\hline
\end{tabular}

Table 4: LULC classification scheme.

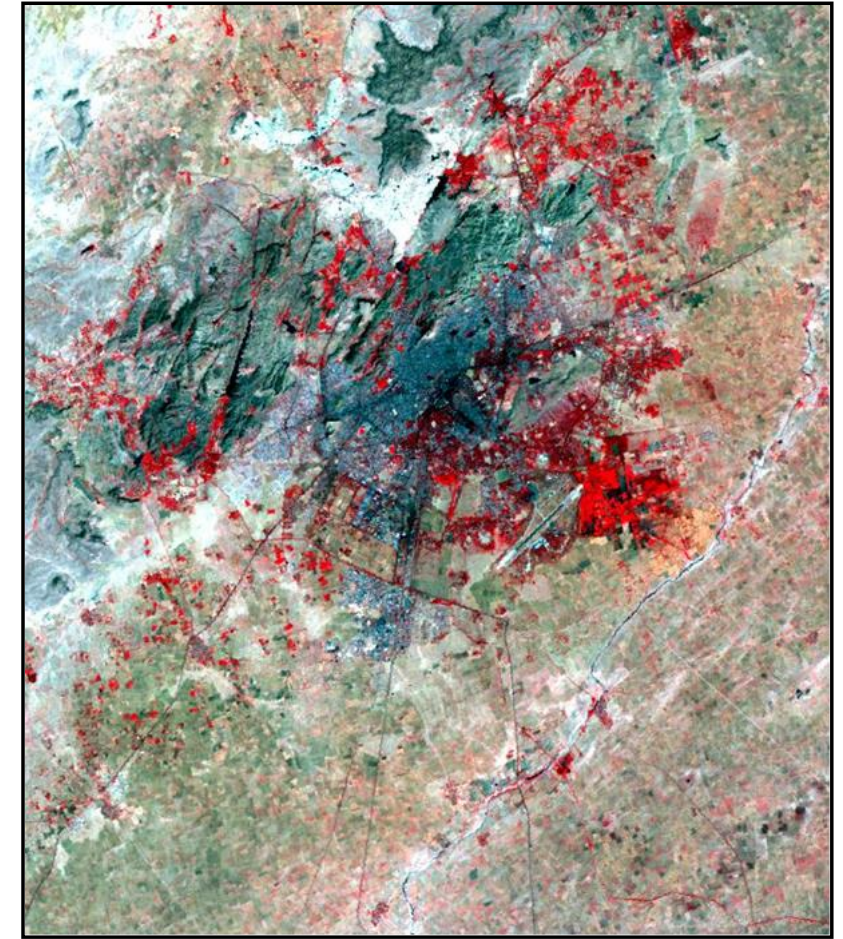

Figure 2. Satellite Image of Study Area (Landsat TM 1990)

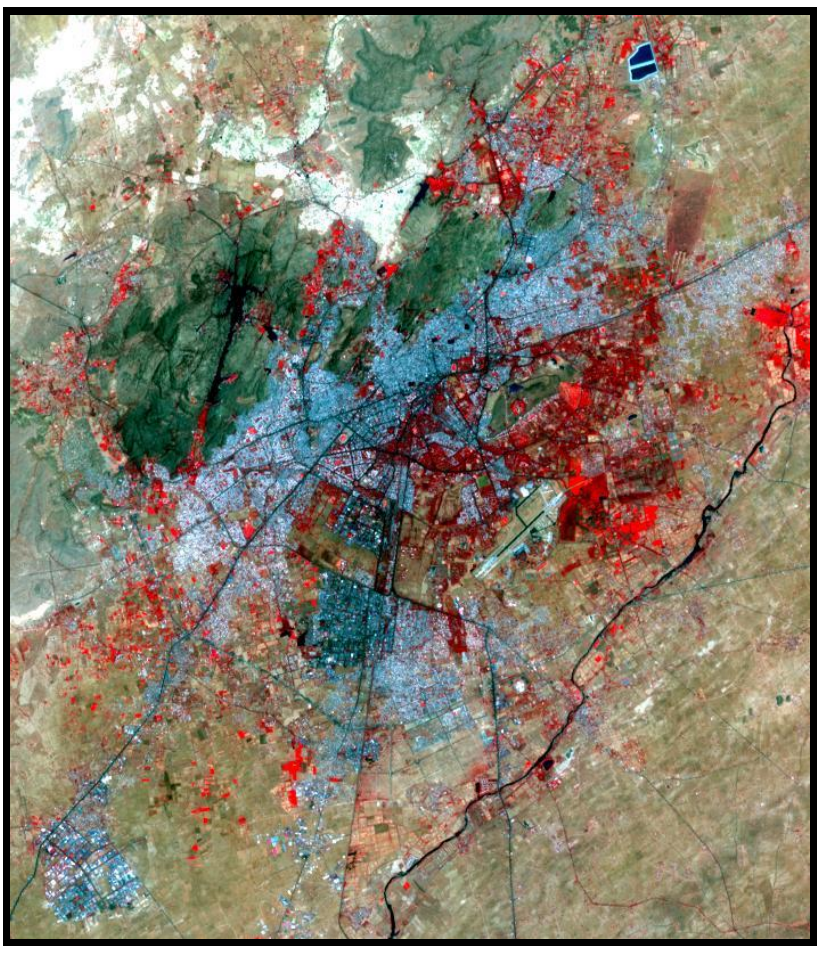

Figure 3. Satellite Image of the Study Area. (Landsat OLI 2018)

\subsection{Methodology}

As mentioned earlier, the objective of this paper is to compare land cover features of Jodhpur in two different years 1990 and 2018. Two Landsat image were taken, and results were recorded and compared simultaneously. Methods of finding result were same for each image and the procedure followed was: 
- Different bands are used in formation of image. All the bands were imported in the software with the help of new file builder, where all the bands got reordered to avoid any error in getting results.

- $\quad$ Georeferenced images are usually considered for analysing remote sensing, due to its application like calculating areas or finding the position on globe. Registration tool is used for georeferencing image. Ground control points (GCPs) are selected from Image windows or Vector windows, and further these points are used in Image-to-Map to select GCPs for image-to-map registration.

- Then images were resized with the help of Resizing Data (Spatial/Spectral). The function of the tool is to resize the image and/or perform image spatial or spectral subsetting, as well as use the resize function to create new images of any size or aspect ratio. Samples and Line of image are picked to get the image of required aspect ratio.

- Then ROIs (Regions of interest) are created. ROIs are portions of images, either selected graphically or by thresholding. The regions can be irregularly-shaped and was used in extracting statistics for classifying.

- Once ROIs are created, maximum likelihood function is used. Maximum likelihood classification is used for calculating the probability of a particular pixel assigned to a given class which defines LULC. Maximum likelihood classification assumes the statistics for every class in each band are normally distributed. Maximum likelihood classification is calculated for each pixel in the image by following discriminant functions (Richards, 1999):

$$
g_{i} \cdot \ln p(\omega)_{-1 / 2} \ln \Sigma_{i}{ }_{-}^{1 / 2}\left(\mathrm{x}-m_{i}\right)^{t} \Sigma_{i}^{-1}\left(\mathrm{x}-m_{i}\right)
$$

Where: $\mathrm{i}=$ class

$\mathrm{x}=\mathrm{n}$-dimensional data (where $\mathrm{n}$ is the number of bands)

$p(\omega)=$ probability that class $\omega_{i}$ occurs in the image and is assumed the same for all classes

$\sum^{\Sigma_{i}}=$ determinant of the covariance matrix of the data in class $\omega_{i}$

$\Sigma-1$

$\Sigma_{\mathrm{i}}^{-1}=$ its inverse matrix

$\mathrm{m}_{\mathrm{i}}=$ mean vector

- Select classification output to File or Memory.

- Once after getting results from maximum likelihood, we need to open the result image. Once we get that image, one need to go to overlay and after selecting overlay classification tool is chosen. We get interactive class tool input file option. Then chosen the image and interactive class tool appears. All the classes we need to get results of are selected and we get area of the region.

- GCP Points were collected for verification of doubtful areas. Based on the GCPs, the misclassified areas were corrected using ENVI software. The error matrix and Kappa methods were used to evaluate the classification mapping accuracy (Rawat and Kumar,2015; Yadav and Borana, 2017).

\section{RESULTS AND DISCUSSION}

The study area has seven LULC categories, namely: urban area, mining area, vegetation, water bodies, rock outcrops and other area (Borana et al., 2017). The LULC Classifications results for 1990 and 2018 are illustrated through Figure 3 and 4. Over twenty-eight years (1990-2018), the changes in area coverage varied from one LULC class to another is shown in Table-5-7. Change detection is made possible by Remote Sensing technology in less time and with better accuracy (Kachhwala, 1985). Accuracy assessment of the LULC classification results were measured using error matrix and Kappa methods, an overall accuracy of $871.18 \%$ for 1990 and $89.22 \%$ for 2018 . The Kappa coefficients for year 1990 and year 2018 maps were 0.801 and 0.892 respectively.

\begin{tabular}{|l|c|c|c|}
\hline Class Name & Npts & Pct & Total Area \\
\hline Urban Area & {$[35596]$} & $5.269 \%$ & $28.615 \mathrm{Km}^{2}$ \\
\hline Vegetation & {$[13782]$} & $8.828 \%$ & $45.07 \mathrm{Km}^{2}$ \\
\hline Mining Area & {$[46236]$} & $7.25 \%$ & $37.172 \mathrm{Km}^{2}$ \\
\hline Water bodies & {$[52611]$} & $2.927 \%$ & $14.943 \mathrm{Km}^{2}$ \\
\hline Rock outcrops & {$[58639]$} & $9.020 \%$ & $47.142 \mathrm{Km}^{2}$ \\
\hline Other area & {$[428173]$} & $66.705 \%$ & $344.228 \mathrm{Km}^{2}$ \\
\hline \multicolumn{1}{|c|}{ Total } & {$[5,76,398]$} & $100 \%$ & $510.535 \mathrm{Km}^{2}$ \\
\hline
\end{tabular}

Table 5. Land cover/land use classes and area (1990)

\begin{tabular}{|l|c|c|c|}
\hline \multicolumn{1}{|c|}{ Class Name } & Npts & Pct & Total Area \\
\hline Urban & {$[104643]$} & $18.309 \%$ & $135.765 \mathrm{Km}^{2}$ \\
\hline Water body & {$[4965]$} & $0.869 \%$ & $8.483 \mathrm{Km}^{2}$ \\
\hline Vegetation & {$[84045]$} & $14.705 \%$ & $75.146 \mathrm{Km}^{2}$ \\
\hline Mining Area & {$[11990]$} & $2.098 \%$ & $10.721 \mathrm{Km}^{2}$ \\
\hline Rock outcrops & {$[47009]$} & $8.225 \%$ & $46.166 \mathrm{Km}^{2}$ \\
\hline Other area & {$[318884]$} & $55.794 \%$ & $286.564 \mathrm{Km}^{2}$ \\
\hline \multicolumn{1}{|c|}{ Total } & {$[571539]$} & $100 \%$ & $511.029 \mathrm{Km}^{2}$ \\
\hline
\end{tabular}

Table 6. Land cover/land use classes and area (2018)

\begin{tabular}{|l|c|c|}
\hline \multicolumn{1}{|c|}{ Class Name } & Change in Area & $\begin{array}{c}\text { Change in } \\
\text { Percentage* }\end{array}$ \\
\hline Urban & $107.15 \mathrm{Km}^{2}(\uparrow)$ & $13.04 \%(\uparrow)$ \\
\hline Water Body & $6.46 \mathrm{Km}^{2}(\downarrow)$ & $2.058 \%(\downarrow)$ \\
\hline Vegetation & $30.076 \mathrm{Km}^{2}(\uparrow)$ & $5.877 \%(\uparrow)$ \\
\hline Mining Area & $26.451 \mathrm{Km}^{2}(\downarrow)$ & $5.152 \%(\downarrow)$ \\
\hline Rock outcrops & $0.976 \mathrm{Km}^{2}(\downarrow)$ & $0.795 \%(\downarrow)$ \\
\hline Other Area & $57.664 \mathrm{Km}^{2}(\downarrow)$ & $10.911 \%(\downarrow)$ \\
\hline
\end{tabular}

( $\uparrow$ Indicates increase; $(\downarrow)$ Indicates decrease

*Change in percentage with respect to total area

Table-7. Land cover/land use classes and change detection (1990 to 2018) 


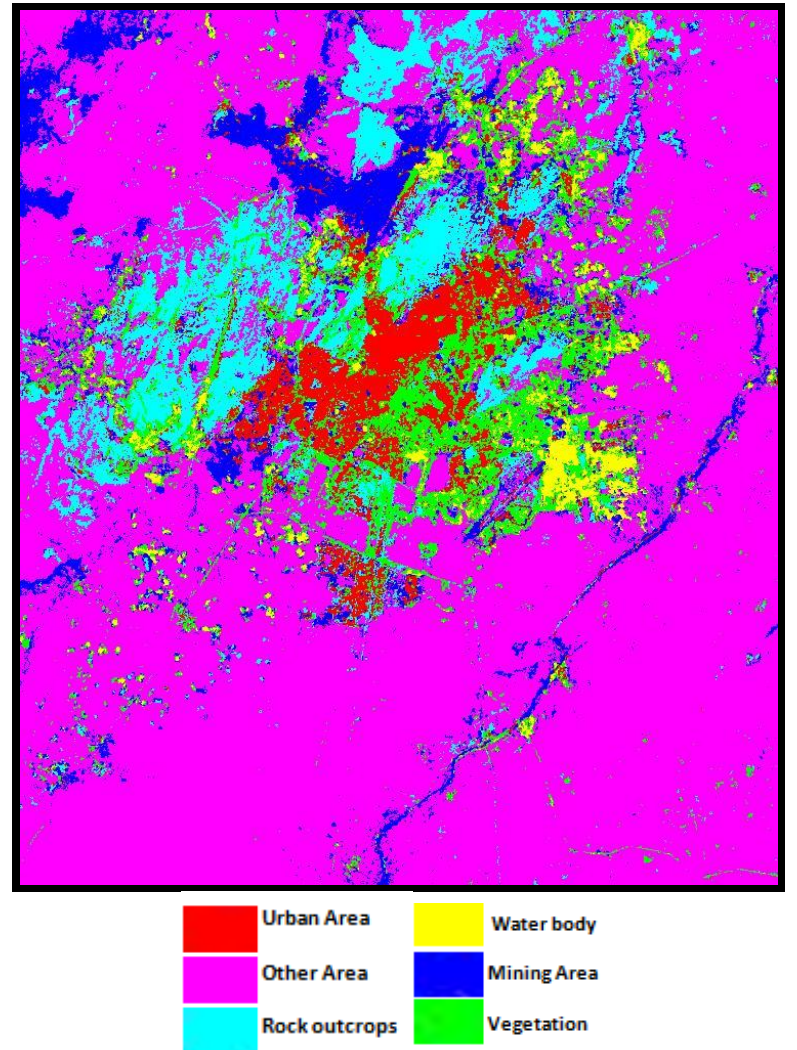

Figure 4. Classified map outputs (1990).

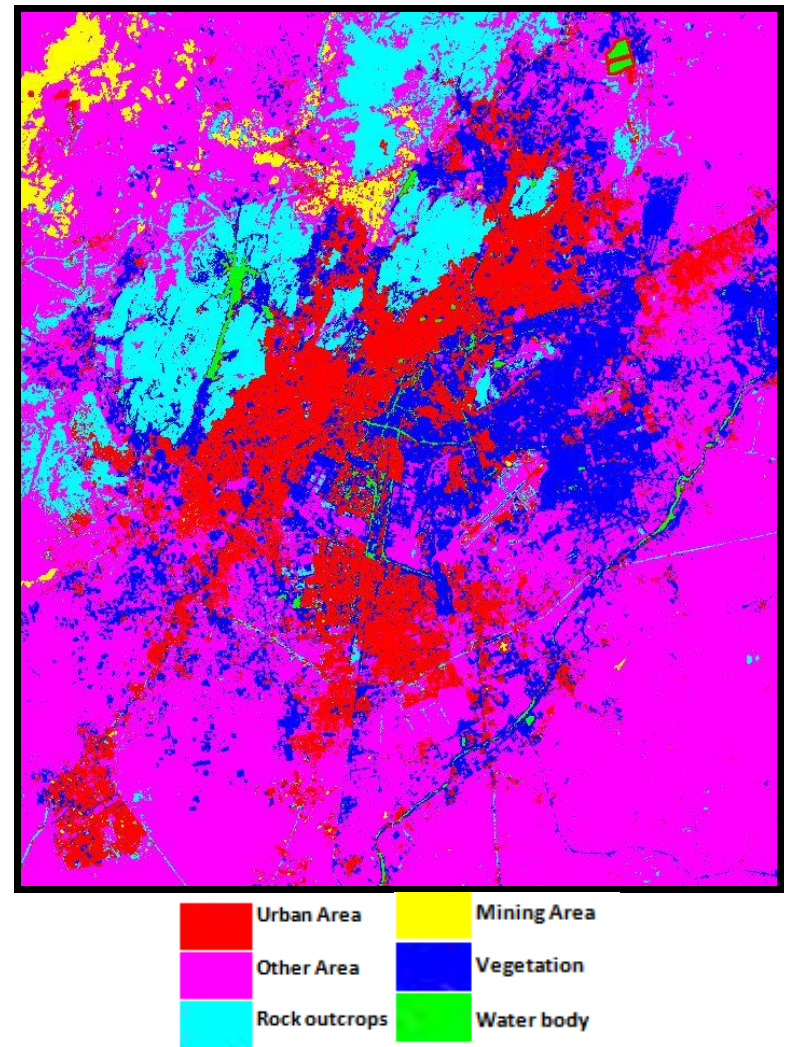

Figure 5. Classified map outputs (2018).

It can be learnt from figures 4,5 and tables 4 to 6 that the urban sprawl has increased by $13.04 \%$ and vegetation cover has also increased by $5.9 \%$. The increase in the mining area is due to vegetation over old mining remnants. The mining area is decreased by $5.2 \%$ but it has shifted from one side of the city to the other side. The mining area and surrounding urban sprawl has inadequate vegetation cover due to active mining. A judicious mine closure plan can positively change LULC and benefit urban planning of the case study. Parihar (1993) has extensively worked for mine closure plans and suggestive measures of his study can be implemented in augmenting LULC cover. The city administration can notice inadequacy in vegetation area and water bodies. A systematic mining activity can resolve both the issue of vegetation and water storage bodies. The outputs from the remote sensing shall be useful in the implementation of AMRUT policy for urban growth of Jodhpur city. Also updated data also be useful in land use planning for achieving sustainable development for present and future demands of the city.

\section{CONCLUSIONS}

RS output has frequently been used to help in the policies making and provides land use-land cover patterns. The analysis techniques are used to map LULC change at landscape level. In Jodhpur City, Urban area and Vegetated area has increased and there has been decrease in other areas such as Rock outcrops, mining area, water bodies and other area. Urban area in 1990 was $28.615 \mathrm{Km}^{2}$ or $5.269 \%$ of the entire area and in 2018 is $135.765 \mathrm{Km}^{2}$. Vegetated area in 1990 was $45.07 \mathrm{Km}^{2}$ or $8.828 \%$ of the entire area and in 2018 is $14.705 \%$ of the entire area. Water Body in 1990 was $14.943 \mathrm{Km}^{2}$ or $2.927 \%$ of the entire area and in 2018 is $8.483 \mathrm{Km}^{2}$ or $0.869 \%$ of entire area. Rock outcrops area in 1990 was $47.142 \mathrm{Km}^{2}$ or $9.020 \%$ of the entire area and in 2018 is $46.166 \mathrm{Km}^{2}$ or $8.225 \%$ of entire area. Mining area in 1990 was $37.172 \mathrm{Km}^{2}$ or $7.25 \%$ of the entire area and in 2018 is $10.721 \mathrm{Km}^{2}$ or $2.098 \%$ of entire area. Other area in 1990 consisted of $344.228 \mathrm{Km}^{2}$ or $66.705 \%$ of the entire area and in 2018 is $286.564 \mathrm{Km}^{2}$ or $55.794 \%$ of entire area. The present study shows that remote sensing is an important technology for LULC temporal analysis and classification mapping. Change detection is made possible by this technology in less time and with better accuracy. The data generation will be useful for the town planning development for proper land planning with required infrastructure in each land development area of the city.

\section{ACKNOWLEDGEMENT}

The authors are thankful to the Director Defence Laboratory, Jodhpur for his help during the study. The authors are also thankful to Head Remote Sensing Group for his critical suggestions and encouragement. The first two authors sincerely acknowledge Defence Laboratory for generously extending facilities for their summer internship from respective educational institutes.

\section{REFERENCES}

Herold M, Scepan J, Clarke K (2002) The use of remote sensing and landscape metrics to describe structures and changes in urban land uses. Environment and Planning 34: 1443-1458.

Richards, J.A., 1999, Remote Sensing Digital Image Analysis, Springer-Verlag, Berlin, p. 240.

Lillesand TM, Kiefer RW, Chipman JW (2004) Remote Sensing and Image Interpretation. John Wiley \& Sons, New Jersey, USA. 
Bhagawat Rimal (2011). Urban Growth and Land Use /Land Cover Change of Pokhara Sub-Metropolitan City, Nepal. Journal of Theoretical and Applied Information Technology, Vol.26, No. 2, ISSN 1992-8645.

Borana, S.L., Yadav,S.K and Parihar, S.K., Using Remote Sensing and GIS to Monitor Land Use-Land Cover Change in Jodhpur city and Surrounding Area, Int. J. of Innovative Research in Science, Engineering and Technology, Vol. 6, Issue 10, 2017, Page No.20369- 20375.

Campbell, J., B. 2002. Introduction to Remote Sensing - third edition. Taylor and Francis, London. p. 621.

Jensen, R.,J. Gatrell, and D. McLean. 2005. Geospatial Technologies in Urban Environments. New York : Springer.

Setturu Bharath, \& Ramachandra, T. V. (2012). Landscape dynamics of Uttara Kannada district. LAKE 2012: National Conference on Conservation and Management of Wetland Ecosystems.

Parihar, S.K. (1993) Land use planning of sandsstone quarrying area around Jodhpur, M.E. Thesis, J.N. Vyas University, Jodhpur.

Yadav, S.K and Borana, S.L., Change Detection Analysis of Urban Land Use Using IRS L-3 Data of Jodhpur City and Surrounding Area, Int. J. of Informative \& Futuristic Research, Volume 5 Issue 3, 2017, Page No. 8872-8877.

T.V. Ramachandra, Bharath H. Aithal, Spatio-Temporal Pattern of Landscape Dynamics in Shimoga, Tier II City, Karnataka State, India, International Journal of Emerging Technology and Advanced Engineering, Volume 2, Issue 9, September 2012.

J.S. Rawat and Manish Kumar, Monitoring land use/cover change using remote sensing and GIS techniques: A case study of Hawalbagh block, district Almora, Uttarakhand, India, The Egyptian Journal of Remote Sensing and Space Sciences (2015) $18,77-84$.

Kachhwala, T.S., 1985. Temporal monitoring of forest land for change detection and forest cover mapping through satellite remote sensing. In: Proceedings of the 6th Asian Conference on Remote Sensing. National Remote Sensing Agency, Hyderabad, pp. $77-83$.

Borana S. L. and Yadav S.K., Accuracy Assessment of Land Cover Classification in Jodhpur City Using Remote Sensing and GIS, Int. J. of Advanced Research in Computer and Communication Engineering, Vol. 6, Issue 10, 2017, Pg .220224. 